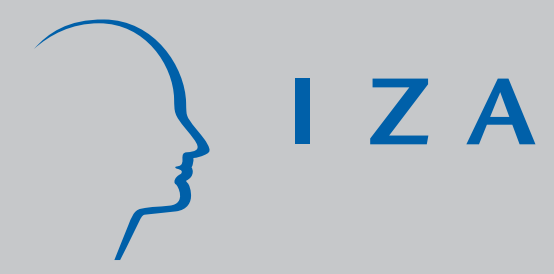

IZADP No. 2054

Should You Allow Your Agent to Become Your Competitor? On Non-Compete Agreements in Employment Contracts

Matthias Kräkel

Dirk Sliwka

March 2006 


\title{
Should You Allow Your Agent to Become Your Competitor? On Non-Compete Agreements in Employment Contracts
}

\author{
Matthias Kräkel \\ University of Bonn and IZA Bonn \\ Dirk Sliwka \\ University of Cologne and IZA Bonn
}

Discussion Paper No. 2054

March 2006

IZA

P.O. Box 7240

53072 Bonn

Germany

Phone: +49-228-3894-0

Fax: +49-228-3894-180

Email: iza@iza.org

\begin{abstract}
Any opinions expressed here are those of the author(s) and not those of the institute. Research disseminated by IZA may include views on policy, but the institute itself takes no institutional policy positions.

The Institute for the Study of Labor (IZA) in Bonn is a local and virtual international research center and a place of communication between science, politics and business. IZA is an independent nonprofit company supported by Deutsche Post World Net. The center is associated with the University of Bonn and offers a stimulating research environment through its research networks, research support, and visitors and doctoral programs. IZA engages in (i) original and internationally competitive research in all fields of labor economics, (ii) development of policy concepts, and (iii) dissemination of research results and concepts to the interested public.
\end{abstract}

IZA Discussion Papers often represent preliminary work and are circulated to encourage discussion. Citation of such a paper should account for its provisional character. A revised version may be available directly from the author. 
IZA Discussion Paper No. 2054

March 2006

\section{ABSTRACT}

\section{Should You Allow Your Agent to Become Your Competitor? On Non-Compete Agreements in Employment Contracts ${ }^{*}$}

We discuss a principal-agent model in which the principal has the opportunity to include a non-compete agreement in the employment contract. We show that not imposing such an agreement can be beneficial for the principal as the possibility to leave the firm generates implicit incentives for the agent. The principal prefers to impose such a clause if and only if the value created is sufficiently small relative to the agent's outside option. If the principal can use an option contract for retaining the agent, she will never prefer a strict non-compete agreement.

JEL Classification: D21, D86, J3, K1, M5

Keywords: fine, incentives, incomplete contracts, non-compete agreements, option contract

Corresponding author:

Matthias Kräkel

University of Bonn

Adenauerallee 24-42

D-53113 Bonn

Germany

Email:m.kraekel@uni-bonn.de

\footnotetext{
* We would like to thank the participants of the SFB/TR 15 seminar at the Economic Department of the University of Bonn, in particular our discussant Patrick Schmitz as well as Oliver Gürtler and Patrick Kampkötter for helpful comments and suggestions. Financial support by the Deutsche Forschungsgemeinschaft (DFG), grants KR 2077/2-1 and SFB/TR 15, is gratefully acknowledged.
} 


\section{Introduction}

In July 2005, Google announced the opening of a research and development center in China. The center was to be headed by Dr. Kai-Fu Lee, a renowned well connected computer scientist working for Microsoft in China and reportedly "Microsoft's face in China". Dr. Lee was appointed as President of Google China. But as Microsoft revealed shortly afterwards, Dr. Lee was subject to a non-compete agreement with Microsoft. In 2000 he had signed an agreement providing that, for a period of one year after leaving Microsoft, he would not "accept employment or engage in activities competitive with products, services or projects ... on which [he] worked or about which [he] learned confidential or proprietary information or trade secrets while employed at Microsoft".

Microsoft feared that Dr. Lee would use information he had obtained while working for Microsoft to its competitor Google's advantage. The company immediately went to court in Seattle, Washington. The court issued a restraining order, temporarily forbidding Dr. Lee to work on projects for Google similar to those he performed for Microsoft which included work on search engines and the development of business strategies for the Chinese market. ${ }^{1}$

Hence, non-compete agreements seem to be a very powerful instrument to protect a firm's internal knowledge when this knowledge creates a competitive advantage. Not only in the technology industry loosing an employee to a competitor may have harmful consequences for a firm. Insurance companies, investment banks and lawyers for instance might want to prohibit their employees to be hired by a competitor as those employees might try to take specific clients with them. In addition, such an agreement may also prevent that the employee himself directly turns into a competitor by becoming selfemployed. Therefore, a puzzling question remains: why do we not observe a non-compete agreement in all existing employment contracts?

In this paper, we want to investigate reasons for a firm not to use such an agreement in an employment contract. A first possible reason may be

\footnotetext{
${ }^{1}$ Description based on Baker \& Hostetler LLP Executive Alert, September 2005.
} 
given by legal problems to enforce such agreements. For instance, in the US the possibilities to enforce a non-compete agreement differ between the federal states. In the above mentioned case, Google itself filed a separate suit against Microsoft at a Californian court claiming that the agreement was unenforceable under Californian law. Indeed Californian courts are claimed to be much less likely to enforce a non-compete agreement. ${ }^{2}$ However, this was turned down as Dr. Lee's contract provided that possible litigation had to be in Washington state.

In this paper, we show that based on incentive considerations an employer may not want to impose such a contractual provision. As we will show, this reason may lead a firm to forgo the possibility to impose a noncompete agreement even if the expected future loss to itself is larger than the expected future gain to the employee when leaving. To understand the basic idea note the following: It is often quite hard for firms to measure the specific performance of individual employees objectively. Hence, firms must often rely on indirect measures to reward performance such as for instance the number of patents granted for researchers or the turnover in a certain area for sales persons. Such measures are often noisy or measure only the performance of a whole team of agents. The literature on incentive contracts contains numerous examples showing that this typically leads to costly and inefficiently low powered incentive schemes. Even if the firm is able to observe individual performance, there is the problem to give a credible commitment to honor exceptional performance when it is unverifiable in court.

But note that the fact that an employee gets an attractive job offer may in itself be a signal that he has built some form of valuable human capital. Moreover, this will be a signal on his individual performance. Imposing a non-compete agreement will not prohibit that such a signal occurs. Even when he has signed such an agreement the employee can come up with external offers when he successfully built valuable human capital. But with such an agreement the firm has an incentive ex-post to deny the agent's success. However, when not imposing the agreement the firm can still convince the employee ex-post to stay but it has to raise the employee's wage. Therefore,

\footnotetext{
${ }^{2}$ See Gilson (1999).
} 
forgoing such an agreement can be a device for the principal to commit credibly to honor high performance in the future. This creates implicit incentives for the agent in addition to explicit incentives generated by bonus payments based on objective measures.

Instead of strict non-compete agreements, the employer may use contractual arrangements that are less problematic to be enforced by law. In practice, courts seem to find it difficult to verify that the non-compete agreement is reasonable for protecting the employer's legitimate interests. However, courts are more prone to enforce contractual solutions where an employee voluntarily decides not to become a competitor and receives a predetermined amount of money as compensation from the employer. In Section 5, we therefore investigate the optimal use of such option contracts. We also analyze a related solution in which the employee has to pay a fine to the employer when leaving the firm. We show that option and fine contracts are superior to a strict non-compete agreement as they allow the employer to fine-tune incentives. Indeed, similar contractual solutions can be found in practice. The first one is called forfeiture-for-competition clause. ${ }^{3}$ Here, post-employment benefits are linked to the employee's subsequent career. If he becomes a direct competitor of his former employer or accepts a position at a rival firm, the employee will forfeit the post-employment benefits. The second alternative are garden leave provisions developed in England and Wales and now widely used also in the US: ${ }^{4}$ Employees receive their full salary but have to remain inactive in the labor market by staying at home.

The paper is related to other fields in the existing literature. First, there are parallels to the literature on explicit versus implicit incentives (e.g. Baker, Gibbons and Murphy 1994, 2002, Schmidt and Schnitzer 1995). However, that literature typically discusses the interplay of informal agreements and formal contracts within a repeated-game setting. In our paper, the principal can either permit implicit incentives by not imposing a non-competition clause or she can prohibit implicit incentives by using such a clause. There is also a connection to the career concerns literature where implicit incentives

\footnotetext{
${ }^{3}$ See, for example, Starr and Strauss (2004).

${ }^{4}$ See e.g. Lembrich (2002).
} 
are generated by an agent's career prospects (Holmström 1982, Gibbons and Murphy 1992).

Moreover, there exists a related literature on labor mobility as a source of technology spillovers which discusses organizational solutions for preventing knowledge transfer (e.g. Pakes and Nitzan 1983, Ronde 2001, Rajan and Zingales 2001, Kräkel 2005). Possible solutions are the division of labor into different tasks, the optimal design of the hierarchical structure or simply withholding of knowledge by the principal. This paper concentrates on noncompete agreements as an alternative solution which has not been addressed in this context.

Furthermore, there are papers that directly deal with non-compete agreements and other instruments to limit the agent's contractual freedom. Fosfuri and Ronde (2004) and Hellmann and Perotti (2005) discuss non-compete agreements in the context of knowledge spillovers. Whereas Fosfuri and Ronde consider the impact of such agreements on firms' incentives to cluster, Hellmann and Perotti show that allowing the agent to leave the firm reduces the principal's labor costs. Feess and Muehlheusser (2005) analyze the implications of different contract lengths for players in football teams. In their model, shorter contracts increase the players incentives since they open the opportunity for renegotiation after some successful matches.

Finally, the findings of our paper can be interpreted in the context of the incomplete contract literature (e.g. Grossman and Hart 1986, Hart and Moore 1990). In those models, the transfer of ownership increases an agent's outside option and therefore generates incentives. In a sense, the omission of a non-compete clause in our model can be interpreted as giving the agent stronger ownership rights in his own human capital and this makes him work harder.

The paper is organized as follows. In the next section, the model is introduced. Section 3 considers a situation without incentive problems. The optimality of a non-competition clause in the presence of incentive problems is analyzed in Section 4. Section 5 introduces the possibility of a fee which the agent has to pay to the principal in case of leaving the firm. Section 6 concludes. 


\section{The Model}

A firm represented by a principal $P$ hires an agent $A$. Both players are risk neutral. The agent can exert an effort $a$ to create an innovation. He is either successful $\left(I_{A}=1\right)$ or not $\left(I_{A}=0\right)$ and $a$ is the probability that the agent is successful in creating the innovation (i.e. $\operatorname{prob}\left\{I_{A}=1\right\}=a$ ). His costs of effort are $c(a)$ where $c(a)$ is monotonically increasing and strictly convex with $c^{\prime \prime}(a)>0, c^{\prime \prime \prime}(a) \geq 0, c(0)=0, c^{\prime}(0)=0$, and $\lim _{a \rightarrow 1} c^{\prime}(a)=\infty$. The innovation will allow the firm to enter a new market. Not only agent $A$ works on the innovation. Even when he fails, the principal makes the innovation $\left(I_{P}=1\right)$ with a given probability $\operatorname{prob}\left\{I_{P}=1\right\}=p$. With probability $\operatorname{prob}\left\{I_{P}=0\right\}=1-p$ the principal is not successful. Then principal and agent learn whether the innovation is made $\left(\max \left\{I_{A}, I_{P}\right\}=1\right)$. The event of an innovation is verifiable but not the identity of the innovator. ${ }^{5}$ Hence, an incentive contract for the agent can only be conditional on the fact that an innovation has been made. The optimal bonus contract therefore consists of a base wage $w$ and a bonus $b$ paid to the agent in case of an innovation. We assume that the agent is protected by limited liability such that $w \geq 0$ and $w+b \geq 0$ and has a reservation wage of 0 .

If an innovation has been made, the principal can enter the new market. But at the same point the agent may quit the firm. We assume that the agent will have built up industry specific human capital if he himself discovered the innovation $\left(I_{A}=1\right)$. Hence, he may be hired by a competitor or set up his own firm and compete with his former employer. We assume that such an opportunity arises with probability $z$ once the agent himself has discovered the innovation. If the innovation has been made but the agent does not become a competitor of the principal, the latter will earn profits $M>0$. When the agent becomes a competitor the principal's profits are reduced to $D_{P}<M{ }^{6}$ In this case, the agent himself will earn $D_{A}>0$. We assume

\footnotetext{
${ }^{5}$ Note that, in practice, individual performance often is not verifiable. However, the more aggregate a performance measure is, the more likely it will be verifiable by a third party. At least, at the highest level of aggregation - at firm level - there exists a verifiable performance measure: firm profits. Of course, the higher the level of aggregation the less accrurate the measure will be in describing individual success.

${ }^{6}$ Note that if the agent has made the innovation and leaves the firm, the principal will
} 
that it is verifiable whether the agent separates from the principal. However, it is not verifiable whether the agent can indeed earn $D_{A}$ when leaving the firm. We can think of a situation, in which the principal is a monopolist when the agent does not separate from her, but becomes a duopolist in case of separation. However, the following results do neither need explicit assumptions on the number of competitors in the market nor on the form of competition.

The principal has the possibility to impose a non-compete agreement in the initial contract. Such a clause will forbid the agent to become the principal's competitor. Formally, besides the base wage and the bonus, the contract offer contains a supplement $s$ which can either be $s=C$ if a noncompetition clause is added or $s=N C$ if no clause is chosen by the principal. Our key objective is to investigate whether she will want to impose a noncompetition clause or not. We restrict the analysis to the case of $M \geq$ $D_{A}+D_{P}$. If this condition does not hold it will always be optimal that the agent leaves the firm after an innovation.

Note that of course when the principal does not choose $s=C$ ex-ante she may well try to prevent that the agent enters the market ex-post by making a retention offer. We assume that the principal has all the bargaining power and makes a take-it-or-leave-it offer at each stage.

still be able to enter the new market since the prototype of the innovation belongs to the firm. 
The time-schedule of the game is as follows.

\begin{tabular}{|c|c|c|c|c|}
\hline 1 & 2 & 3 & 4 & 5 \\
\hline $\begin{array}{c}P \text { offers con- } \\
\text { tract }(w, b, s) \\
A \text { decides } \\
\text { on acceptance }\end{array}$ & $\begin{array}{c}A \text { chooses } \\
\text { effort } \\
\text { level } a\end{array}$ & $\begin{array}{c}A \text { and } P \\
\text { observe } \\
I_{A} \text { and } I_{P}\end{array}$ & $\begin{array}{c}\text { If } I_{A}=1 \\
\text { and } s=N C \\
A \text { may sepa- } \\
\text { rate with } \\
\text { probability } z\end{array}$ & $\begin{array}{l}P \text { makes } \\
\text { retention } \\
\text { offer; } \\
\text { payments }\end{array}$ \\
\hline
\end{tabular}

First, the principal offers a contract $(w, b, s)$ to the agent who then has to accept or reject the offer. When accepting, the agent chooses effort $a$. Thereafter, both principal and agent observe individual success or failure in discovering the innovation. If the agent has been successful and no noncompete agreement has been chosen, with probability $z$ the agent will get the opportunity to separate from the principal. In this case, the principal can offer a lump-sum payment to make the agent stay. Finally, all contractual payments are made.

\section{No Incentive Problem}

As a reference case we first consider the scenario where the agent's effort level can be specified in the contract and, hence, no bonus is needed to generate incentives. Still the principal may either impose a non-competition clause or she may not. First, we investigate the case where such clause is chosen. The agent's participation constraint requires $w-c(a) \geq 0$. In optimum, it will be binding and the principal solves

$$
\max _{a}(p+a(1-p)) M-c(a)
$$

The first-order condition is $(1-p) M=c^{\prime}(a)$ and the first-best effort level is therefore given by

$$
a^{F B}=A((1-p) M)
$$


where $A(x)=c^{\prime-1}(x)$. The principal's net profits are $\left(p+a^{F B}(1-p)\right) M-$ $c\left(a^{F B}\right)$.

Now we consider the case $s=N C$ where no non-competition clause is imposed. Because of $M \geq D_{A}+D_{P}$ the principal will always make a retention offer when the agent gets the opportunity to become self-employed or an employee of a competing firm. As the principal has all the bargaining power she will pay an amount of $D_{A}$ to the agent. His participation constraint is therefore

$$
w-c(a)+a z D_{A} \geq 0 .
$$

If the participation constraint is binding the principal will be indifferent between $s=C$ and $s=N C$ as the only effect of the clause is that an amount of $a z D_{A}$ is paid to the agent in form of a higher wage $w$ rather than as the expected outcome of the renegotiation when the agent gets the chance to leave. But if the participation constraint is not binding the optimal wage $w$ will be equal to zero and the principal is clearly worse off without the clause as she pays too much to the agent.

Hence, the principal will always be at least weakly better off with a noncompete agreement so that it is optimal for her to impose such a clause when there is no incentive problem. We now check whether the optimality of a noncompete agreement will still hold if the principal has to motivate the agent to work hard by using a performance contingent contract.

\section{The Provision of Incentives}

\subsection{Optimal Contract with a Non-Compete Agreement}

Now $a$ is no longer verifiable and the principal can pay a bonus $b$ in case of an innovation. First, consider the case where a non-competition clause is imposed. For a given contract $(w, b, C)$ the agent maximizes his expected utility

$$
w+(p+a(1-p)) b-c(a) .
$$


The first-order condition $(1-p) b=c^{\prime}(a)$ yields the incentive constraint

$$
a=A((1-p) b)
$$

where again $A(x)=c^{\prime-1}(x)$. The limited liability constraint requires that $w, w+b \geq 0$. Hence, the agent's utility is always non-negative and therefore the participation constraint is implied by the limited liability constraint. It is straightforward to see that any optimal contract will have a zero base wage $w$. Hence, the principal solves

$$
\max _{b}(p+A((1-p) b)(1-p))(M-b)
$$

We obtain the following result:

Proposition 1 When imposing a non-compete agreement in the contract the principal will provide incentives to the agent by paying a bonus in case of an innovation if $M$ is strictly larger than a cut-off value $\bar{M}_{C}=\frac{p}{A^{\prime}(0)(1-p)^{2}}$. In that case, the bonus payment is characterized by

$$
b_{C}=M-\frac{p+A\left((1-p) b_{C}\right)(1-p)}{A^{\prime}\left((1-p) b_{C}\right)(1-p)^{2}} .
$$

The implemented effort level will be smaller than the first-best effort level.

\section{Proof:}

The first derivative of the principal's objective function with respect to $b$ is

$$
A^{\prime}((1-p) b)(1-p)^{2}(M-b)-(p+A((1-p) b)(1-p))
$$

The principal will impose a positive bonus and we will have an interior solution if and only if this expression is strictly positive at $b=0$ which is the case when $M>p /\left(A^{\prime}(0)(1-p)^{2}\right)$. In that case we can solve the first-order condition for $b$ and obtain expression (4). ${ }^{7}$ By inserting this expression into

\footnotetext{
${ }^{7}$ Substituting for $b$ in the second-order condition according to (4) yields that all stationary points are local maxima. However, for more than one maximum we must have at least one local minimum which contradicts the finding before. Hence, (4) describes the global maximum.
} 
(3) it can directly be seen that the chosen effort level is smaller than the first-best effort level.

Due to the agent's limited liability, setting incentives is always costly since the agent earns a rent. As the identity of the innovator is unverifiable the agent would earn a bonus with probability $p$ even when exerting no effort at all which aggravates the problem and raises the costs of inducing incentives. Therefore, the principal will only provide incentives if $M$ is sufficiently large.

Furthermore, note that the cut-off $\bar{M}_{C}$ is monotonically increasing in $p$. This has two reasons. First, for higher values of $p$ the principal is less dependent on the agent to create the innovation and, hence, providing incentives to the agent is less important. But in addition, higher values of $p$ lead to stronger free riding by the agent (see (3)) and this makes setting incentives more costly.

\subsection{Optimal Contract when the Agent may Quit}

We start by investigating the point in the time-schedule where the agent may get the chance to leave the firm given $s=N C$. If the agent does not have the opportunity to work for a competitor or to become self-employed the game of course ends. But when he gets this opportunity after coming up with the innovation the principal can decide whether to keep him. Note that in this case the principal will always be better off when retaining the agent. As she has all the bargaining power she will pay a lump-sum of $D_{A}$ to the agent and her profits are reduced to $M-b-D_{A}$ when the agent gets the opportunity to quit which is the case with probability $a z$. The principal's expected profits are $(p+a(1-p))(M-b)-a z D_{A}$ and the agent's objective function is given by

$$
(p+a(1-p)) b+a z D_{A}-c(a)
$$

The first-order condition

$$
(1-p) b+z D_{A}=c^{\prime}(a)
$$


yields

$$
a=A\left((1-p) b+z D_{A}\right)
$$

It is straightforward to see from a comparison of (3) and (6) that for a given bonus payment the agent now works harder. Making the innovation becomes more attractive as it may open up the opportunity for the agent to get attractive outside offers or to set up his own firm. But of course the principal also looses as her profits are reduced when the agent may threaten to quit. Again $w=0$ and the participation constraint will always be satisfied.

Given $s=N C$ the principal therefore solves

$$
\max _{b}\left(p+A\left((1-p) b+z D_{A}\right)(1-p)\right)(M-b)-A\left((1-p) b+z D_{A}\right) z D_{A}
$$

We obtain the following result:

Proposition 2 When not imposing a non-compete agreement in the contract the principal will provide explicit incentives to the agent by paying a bonus in case of an innovation if $M$ is strictly larger than a cut-off value $\bar{M}_{N C}=$ $\frac{z D_{A}}{1-p}+\frac{p+A\left(z D_{A}\right)(1-p)}{A^{\prime}\left(z D_{A}\right)(1-p)^{2}}$. This cut-off exceeds the cut-off $\bar{M}_{C}$ when the clause is imposed. The bonus payment is characterized by

$$
b_{N C}=M-\frac{1}{1-p}\left(\frac{p+A\left((1-p) b_{N C}+z D_{A}\right)(1-p)}{A^{\prime}\left((1-p) b_{N C}+z D_{A}\right)(1-p)}+z D_{A}\right) .
$$

The optimal bonus is smaller than the bonus with a non-compete agreement.

\section{Proof:}

The first derivative of the principal's objective function is

$$
\begin{gathered}
A^{\prime}\left((1-p) b+z D_{A}\right)(1-p)\left[(1-p)(M-b)-z D_{A}\right] \\
-\left(p+A\left((1-p) b+z D_{A}\right)(1-p)\right) .
\end{gathered}
$$

The principal will impose a positive bonus and we will have an interior solution if and only if this expression is strictly positive at $b=0$ which is the 
case if

$$
\begin{gathered}
A^{\prime}\left(z D_{A}\right)(1-p)^{2} M-\left(p+A\left(z D_{A}\right)(1-p)\right)-A^{\prime}\left(z D_{A}\right)(1-p) z D_{A}>0 \\
\Leftrightarrow M>\frac{p+A\left(z D_{A}\right)(1-p)}{A^{\prime}\left(z D_{A}\right)(1-p)^{2}}+\frac{z D_{A}}{1-p} .
\end{gathered}
$$

As $c^{\prime \prime \prime}(a) \geq 0$ we have $A^{\prime \prime}(x) \leq 0$ and the cut-off value is strictly increasing in $z$. Therefore $\bar{M}_{N C}>\bar{M}_{C}$ for $z>0$. In that case, we can solve (8) for $b$ and obtain expression (7). ${ }^{8}$ Note that this is equal to (4) if $z=0$. By implicit differentiation of the first-order condition (8) we obtain

$$
\frac{\partial b}{\partial z}=-\frac{D_{A}}{1-p}<0
$$

The results from Propositions 1 and 2 are illustrated in Figure 1. The dashed line is $\bar{M}_{C}$ : when a non-compete agreement is imposed the principal pays a bonus only if his revenue from a successful innovation is larger than $\bar{M}_{C}$. The solid line depicts $\bar{M}_{N C}$ as a function of $z$. Without the clause, the principal's decision on whether to pay a bonus depends on $z$ which determines the agent's income when coming up with the innovation. The higher the probability that the agent gets an opportunity to become (or work for) a competitor the higher are his incentives to come up with an innovation. Hence, larger values of $z$ reduce the necessity to induce incentives through an explicit bonus.

\subsection{When Should a Clause be Imposed?}

We now check whether it may be optimal that no non-competition clause is imposed ex-ante even though ex-post the principal is always better off retaining the agent. Note that for $z=0$ we have $\bar{M}_{C}=\bar{M}_{N C}$ as well as $b_{C}=b_{N C}$ and $\Pi_{C}=\Pi_{N C}$ with $\Pi_{s}$ denoting the principal's expected profits

\footnotetext{
${ }^{8}$ Inserting (7) into the second-order condition yields that, if there are more than one stationary points, each of them will correspond to a local maximum. However, if there are at least two local maxima we must have at least one local minimum which leads to a contradiction. Hence, the local maximum described by (7) is the only one.
} 


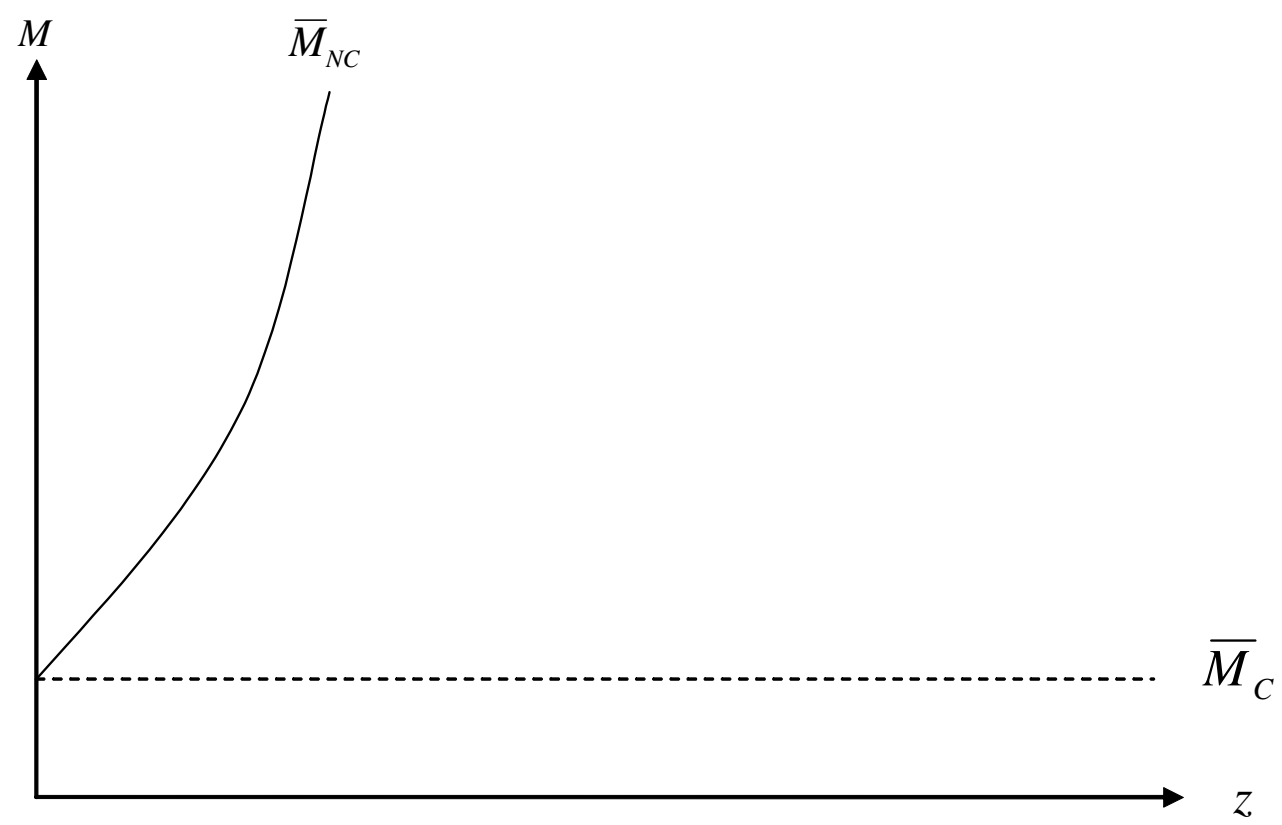

Figure 1: When is a bonus paid?

contingent on the supplement $s \in\{C, N C\}$. Expected profits are therefore given by

$$
\Pi(z, b)=\left\{\begin{array}{cc}
\left(p+A\left((1-p) b+z D_{A}\right)(1-p)\right)(M-b) & \text { if } M>\bar{M}(z) \\
-A\left((1-p) b+z D_{A}\right) z D_{A} & \\
\left(p+A\left(z D_{A}\right)(1-p)\right) M-A\left(z D_{A}\right) z D_{A} & \text { if } M \leq \bar{M}(z) .
\end{array}\right.
$$

with

$$
\bar{M}(z)=\left\{\frac{z D_{A}}{1-p}+\frac{p+A\left(z D_{A}\right)(1-p)}{A^{\prime}\left(z D_{A}\right)(1-p)^{2}}\right.
$$

so that $\bar{M}(0) \equiv \bar{M}_{C}$ and $\bar{M}(z) \equiv \bar{M}_{N C}$ for $z>0$. Comparing the principal's expected profits under a non-competition clause $(s=C$ with $z=0)$ and under no non-competition clause $(s=N C$ with $z>0)$ yields the following results:

Proposition 3 (i) If $M \geq \bar{M}_{N C}$ the principal will never impose a noncompete agreement. 


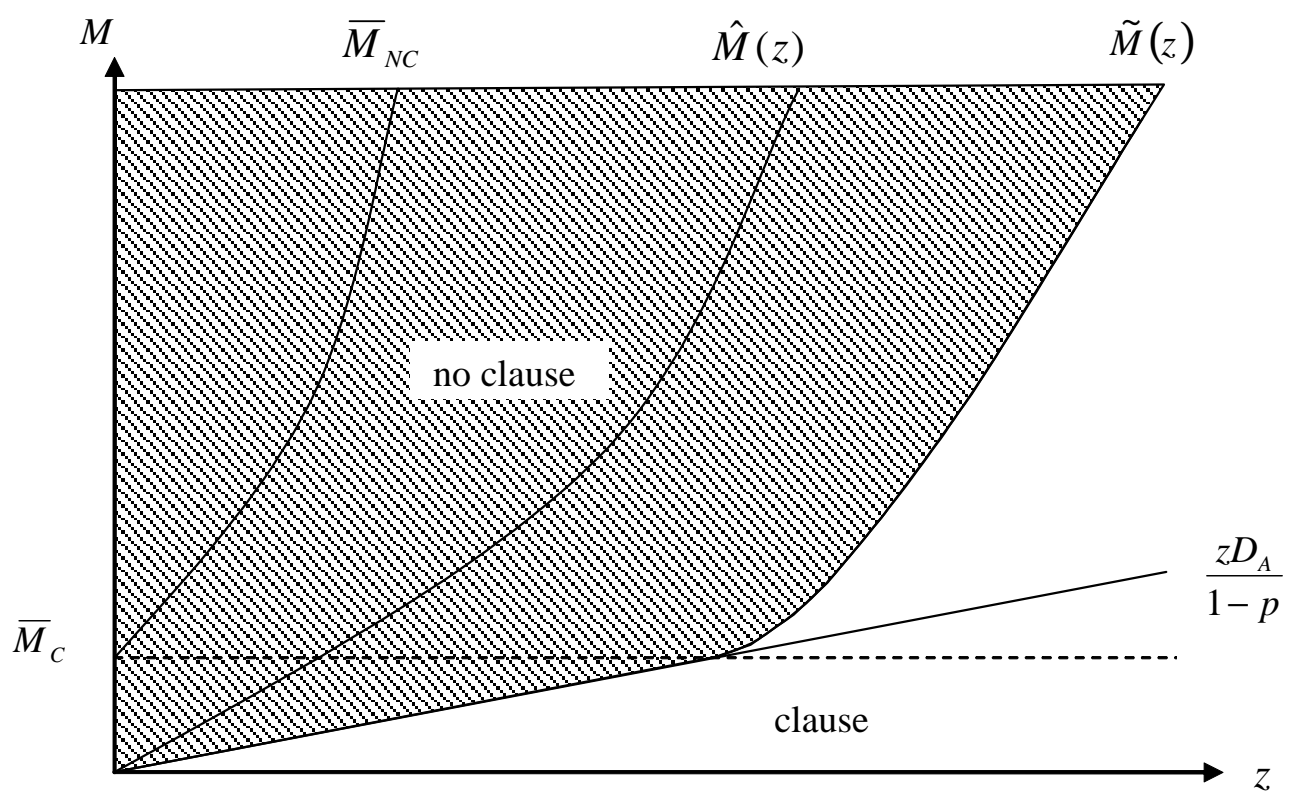

Figure 2: When is the clause imposed?

(ii) If $M \leq \bar{M}_{C}$ a non-compete agreement will be imposed if and only if $M<\frac{z D_{A}}{1-p}$.

(iii) If $\bar{M}_{C}<M<\bar{M}_{N C}$ there will be a monotonically increasing cut-off function $\tilde{M}(z)$ such that the principal will not impose a non-compete agreement if and only if $M$ is larger than this cut-off.

Proof: See Appendix.

The findings of the proposition are illustrated in Figure 2. Note that $z D_{A}$ is the expected value of the agent's outside option in case of success. Hence, the higher $z$ the higher will be the agent's expected wages (i.e. the expected retention offer). The principal therefore faces the following trade-off: when she does not impose the clause, expected wages increase because of a possible outside offer for the agent; but the possible outside offer creates additional incentives for the agent.

The region $M>\bar{M}_{N C}$ describes a situation in which the innovation is so valuable to the principal that she always prefers to induce both implicit 
incentives by not imposing a non-competition clause and explicit incentives by paying an additional bonus.

Of course, the principal can create the same incentives by choosing a non-compete agreement and a higher bonus. However, the agent free rides on the principal's success when explicit incentives are induced - the agent gets the bonus with probability $p$ irrespective of whether he is successful or not which increases his rent. But with implicit incentives there is no free riding because the agent will only earn his outside option $z D_{A}$ if he himself is successful. Hence, using the implicit incentives helps to reduce the agent's rent when incentives are set. Formally, the agent's rent is given by $R=(p+a(1-p)) b+a z D_{A}-c(a)$ with $b=b_{N C}$ and we have that $\partial R / \partial z<0 .{ }^{9}$

However, if $z$ is very large, the additional expected wage costs become prohibitively high for the principal so that she prefers a non-compete agreement and substitutes implicit incentives by higher explicit incentives.

The region $M<\bar{M}_{C}=\frac{p}{A^{\prime}(0)(1-p)^{2}}$ describes a situation in which the principal's probability of being successful, $p$, is large relative to the value of the innovation. In this case, the principal does not choose a positive bonus - neither in the case of a non-competition clause nor in the case without such clause. It is interesting to note that in this region the clause will not be imposed whenever $M \geq \frac{z D_{A}}{1-p}$. Even when explicit incentives are too expensive and therefore never used by the principal, it becomes valuable to introduce implicit incentives as long as the returns from the innovation are sufficiently large relative to the expected wage costs corresponding to the agent's threat of quitting the firm after a success.

Finally, in the region $\bar{M}_{C}<M<\bar{M}_{N C}$ again the trade-off applies. If the principal's returns from the innovation, $M$, are large relative to the agent's outside option, $z D_{A}$, the principal will not impose a non-competition clause; otherwise, she will choose the clause.

\footnotetext{
${ }^{9}$ See Appendix.
} 


\section{Option Contracts}

So far we assumed that the principal can either impose a strict non-compete agreement or non at all. But instead of a strict rule, the principal may well consider including an option to impose a non-compete agreement in the contract. ${ }^{10}$ If such an agreement is legal this option may be tied to a strike price the principal has to pay to the agent ex-post when she decides to enforce the agreement and the choice of the strike price yields an additional instrument to fine-tune incentives. As has been shown for instance by Nöldeke and Schmidt $(1995,1998)$ such option contracts may reduce incentive problems when contracts are incomplete. Hence, it is interesting to study whether an option on a non-compete agreement may be useful in our context.

To investigate this, we assume that the contract may include an option such that the principal can decide to forbid the agent to become a competitor at stage 5 . The contract then consists of a base wage $w$, a bonus payment $b$ and a strike price $\beta$ which the principal has to pay to the agent when she executes the option.

It is straightforward that the principal will again always set $w=0$. Note that the principal's loss when the agent becomes a competitor, $M-D_{P}$, sets an upper bound for the strike price $\beta$. If $\beta>M-D_{P}$, the principal will never execute the option. However, if $\beta=0$ the principal will always execute the option as this decision will be at no costs for her. Since the agent anticipates the principal's future behavior, the scenario $\beta=0$ corresponds to a situation in which the principal has chosen a strict non-compete clause. For ease of notation let $\Delta=M-D_{P}$.

The agent's objective function is given by

$$
(p+a(1-p)) b+a z \beta-c(a)
$$

and the principal's ex-ante expected profits are

$$
(p+a(1-p))(M-b)-a z \beta .
$$

\footnotetext{
${ }^{10}$ We thank Patrick Schmitz for the suggestion to investigate the use of option contracts.
} 
To derive the optimal option contract, the principal chooses the bonus payment $b$ and the strike price $\beta$ in order to maximize this function taking into account the incentive constraint, the limited liability condition requiring that $b, \beta \geq 0$, and the condition that $\beta \leq \Delta$.

Solving this problem we obtain the following proposition:

Proposition 4 If the principal can include an option to enforce a noncompete clause when paying a predetermined strike price $\beta$ to the agent she will always make use of this possibility and choose a strictly positive $\beta$. There exist two cut-off functions $M_{1}(z \Delta)$ and $M_{2}(z \Delta)$ with $M_{1}(z \Delta)<M_{2}(z \Delta)$ so that the following results hold:

(i) If $M<M_{1}(z \Delta)$ the strike price is determined by

$$
\beta=\frac{(1-p) M}{z}-\frac{A(z \beta)}{z A^{\prime}(z \beta)}
$$

and no bonus is paid $(b=0)$.

(ii) If $M_{1}(z \Delta) \leq M \leq M_{2}(z \Delta)$ the strike price is given by $\beta=\Delta$ and no bonus is paid $(b=0)$.

(iii) If $M>M_{2}(z \Delta)$ the strike price is $\beta=\Delta$ and in addition a strictly positive bonus is paid, which is determined by

$$
b=M-\frac{1}{1-p}\left(\frac{p+A((1-p) b+z \Delta)(1-p)}{A^{\prime}((1-p) b+z \Delta)(1-p)}+z \Delta\right) .
$$

Proof: See Appendix.

As before, the principal has two instruments to generate incentives. She can still pay a bonus when an innovation has been made in the firm and she can generate implicit incentives by allowing that the agent may become a competitor. The second instrument has the advantage that the agent only benefits when he himself comes up with the innovation. Without the option to impose a non-compete agreement the second instrument had the disadvantage that the agent's threat to quit the firm can be too expensive. The possibility of including an optional non-compete clause now gives the 
principal an additional degree of freedom to fine-tune implicit incentives. In essence, the option acts as a bonus which will be paid only if the agent himself is successful. ${ }^{11}$ Even though this event is unverifiable, the agent anticipates that he will receive a payment of $\beta$ after coming up with an innovation if he gets the possibility to become a competitor. Hence, the option is always a more effective instrument to set incentives than the bonus as the payment of the strike prize is tied to an individual success by the agent rather than a collective success of the firm. But the use of the option is limited as the strike price cannot exceed the principal's loss from competition $\Delta=M-D_{P}$.

If the value of the innovation is rather small for a given loss from competition, $\Delta$, the principal will only use the option to set incentives. For intermediate values of $M$ she will set the strike price as high as feasible to generate maximum implicit incentives, but still uses no bonus. If $M$ is very large relative to $M-D_{P}$ the principal prefers to set stronger than maximum implicit incentives and offers an additional bonus payment for collective success. It is important to emphasize that, in any case, the strike price is strictly positive, and, hence, the principal will never impose a strict non-compete agreement.

Note that option contracts are not the only feasible instrument to finetune incentives. A different instrument would be to allow the agent to become a competitor but to impose a fine $F$ she has to pay to the principal in this case. Renegotiations will then always lead the principal to make a retention offer to the agent but the value of the offer depends on the initially prescribed fine. Interestingly, such a fine leads to exactly the same outcome as the option contract for a large parameter range. With a fine, the agent receives a retention offer of $D_{A}-F$ when coming up with an innovation. Hence, for $F=D_{A}-\beta$ the fine contract exactly replicates the option contract. However, the use of a fine is limited as it must be non-negative: Otherwise the agent will leave the firm even when he made no innovation. Therefore implicit incentives with a fine contract are limited to a maximum payment of $D_{A}$ in case of an individual innovation by the agent. With an option contract, this

\footnotetext{
${ }^{11}$ Note that, in case (i), $z \beta$ is equal to the optimal bonus payment the principal would choose if $I_{A}$ rather than $\max \left\{I_{A}, I_{P}\right\}$ were verifiable. Hence, the option contract replicates the second best optimal contract given that an individal innovation is verifiable.
} 
maximum payment is $\Delta=M-D_{P}$ which is larger because $M>D_{A}+D_{P}$.

\section{Conclusion}

At first sight, it seems rational for a principal always to introduce a noncompete agreement into the labor contract. Such clause protects her against the danger that the agent could leave the firm and utilize an innovation in direct market competition against his former employer. In the given setting, the principal's preferences in favor of a non-compete agreement are even reinforced by the assumption that ex-post the principal is always interested in retaining the agent. Hence, if she has not chosen such a clause ex-ante, ex-post she would pay the agent his outside option to make him stay. But as we have shown the principal may nevertheless prefer not to impose a non-competition clause. This will be the case if the principal's profits from entering the market are sufficiently large relative to the agent's outside option. If the principal can use an option contract for retaining the agent at a predetermined price, she will even never impose a strict non-compete agreement but always uses the option.

Note that the principal's profits from entering the market can only be fully realized if the agent does not leave the firm. But somewhat counterintuitively, our findings show that the larger these profits the less likely the principal will commit the agent to the firm by using a non-compete agreement. However, since ex-post the principal will always make a retention offer and keeps the agent, the only aspects that play a role are the expected wage costs and the implicit incentives generated by the agent's outside option, and the latter are more valuable if the principal's profits from the innovation are higher. 


\section{Appendix}

Proof of Proposition 3:

(i) When $M \geq \bar{M}_{N C}$ we also have that $M>\bar{M}_{C}$ as $\bar{M}(z)$ is monotonically increasing in $z$. Hence, the principal pays a bonus in both cases. We can then apply the envelope theorem to compute the first derivative of the principal's profit function (10) with respect to $z$ :

$$
A^{\prime}\left((1-p) b+z D_{A}\right) D_{A}\left((1-p)(M-b)-z D_{A}\right)-A\left((1-p) b+z D_{A}\right) D_{A} \text {. }
$$

This expression is strictly positive whenever

$$
(1-p)(M-b)-z D_{A}-\frac{A\left((1-p) b+z D_{A}\right)}{A^{\prime}\left((1-p) b+z D_{A}\right)}>0
$$

As we have interior solutions for the bonus payments we can substitute (7) for $b$ and obtain that the inequality is equivalent to

$$
\frac{p+A\left((1-p) b+z D_{A}\right)(1-p)}{A^{\prime}\left((1-p) b+z D_{A}\right)(1-p)}-\frac{A\left((1-p) b+z D_{A}\right)}{A^{\prime}\left((1-p) b+z D_{A}\right)}>0
$$

which always holds. Hence, the principal always prefers not to impose a clause in that case.

(ii) First note that when no bonus is paid in both settings $\left(M \leq \bar{M}_{C}\right)$, the principal would prefer to impose the clause if

$$
\begin{gathered}
\Pi(0,0) \geq \Pi(z, 0) \Leftrightarrow \\
p M \geq\left(p+A\left(z D_{A}\right)(1-p)\right) M-A\left(z D_{A}\right) z D_{A} \Leftrightarrow \\
M \leq \frac{z D_{A}}{1-p} .
\end{gathered}
$$

Hence, for $M \leq \bar{M}_{C}$ the clause is imposed if and only if $M \leq \frac{z D_{A}}{1-p}$.

(iii) We still have to examine the case where $\bar{M}_{C}<M<\bar{M}_{N C}$. In this region, the principal pays a bonus with a clause and no bonus without. Hence, she 
prefers not to impose the clause whenever

$\left(p+A\left(z D_{A}\right)(1-p)\right) M-A\left(z D_{A}\right) z D_{A}-(p+A((1-p) b)(1-p))(M-b)$

is strictly positive for $b=b_{C}$. We now show that if this condition holds for a certain $M$ it will hold for any $M^{\prime}>M$. This is true if the derivative with respect to $M$ of the left-hand side will always be larger than that of the right-hand side. Suppose that would not be the case. Then (by applying the envelope theorem)

$$
\begin{gathered}
p+A\left(z D_{A}\right)(1-p) \leq p+A((1-p) b)(1-p) \Leftrightarrow \\
z D_{A} \leq(1-p) b \Leftrightarrow \\
z D_{A} \leq(1-p)\left(M-\frac{p+A((1-p) b)(1-p)}{A^{\prime}((1-p) b)(1-p)^{2}}\right) \Leftrightarrow \\
M \geq \frac{z D_{A}}{1-p}+\frac{p+A((1-p) b)(1-p)}{A^{\prime}((1-p) b)(1-p)^{2}} .
\end{gathered}
$$

But as $A($.$) is strictly increasing and concave, this implies$

$$
M \geq \frac{z D_{A}}{1-p}+\frac{p+A\left(z D_{A}\right)(1-p)}{A^{\prime}\left(z D_{A}\right)(1-p)^{2}}
$$

which contradicts $M<\bar{M}_{N C}$. Hence, a cut-off function $\tilde{M}(z)$ must indeed exist and is implicitly defined by setting (11) equal to zero. Since (11) has continuous partial derivatives, from the implicit-function theorem $\tilde{M}(z)$ will also be continuous.

We know already from case (ii) that the clause is not imposed if $M \geq$ $\frac{z D_{A}}{1-p}$ for $M \leq \bar{M}_{C}$. From the paragraph before, we can conclude that for $z<\frac{(1-p) \bar{M}_{C}}{D_{A}}$ the clause is neither imposed for all $M \geq \bar{M}_{C}$. Furthermore, by continuity of the profit function $\tilde{M}\left(\frac{(1-p) \bar{M}_{C}}{D_{A}}\right)=\bar{M}_{C}$. For $z>\frac{(1-p) \bar{M}_{C}}{D_{A}}$ we obtain the slope of $\tilde{M}(z)$ by applying the implicit function theorem and the envelope theorem to (11):

$$
\frac{\partial \tilde{M}(z)}{\partial(z)}=\frac{-A^{\prime}\left(z D_{A}\right)(1-p) M+A^{\prime}\left(z D_{A}\right) z D_{A}+A\left(z D_{A}\right)}{\left(A\left(z D_{A}\right)-A((1-p) b)\right)(1-p)} D_{A} .
$$


We have already shown by contradiction that $z D_{A}>(1-p) b$ in the relevant area. Hence, the denominator must always be positive. The numerator of (12) will be strictly positive, if

$$
\tilde{M}(z)<\frac{A\left(z D_{A}\right)}{A^{\prime}\left(z D_{A}\right)(1-p)}+\frac{z D_{A}}{1-p}:=\hat{M}(z) .
$$

Note that $\tilde{M}\left(\frac{(1-p) \bar{M}_{C}}{D_{A}}\right)<\hat{M}\left(\frac{(1-p) \bar{M}_{C}}{D_{A}}\right)$ and therefore $\tilde{M}(z)$ is strictly increasing at $\frac{(1-p) \bar{M}_{C}}{D_{A}}$. Now suppose that $\frac{\partial \tilde{M}(z)}{\partial z} \leq 0$ for some $z>\frac{(1-p) \bar{M}_{C}}{D_{A}}$ which is equivalent to $\tilde{M}(z) \geq \hat{M}(z)$. This would require that $\tilde{M}(z)$ intersects $\hat{M}(z)$ from below at some point at which (by definition of $\hat{M}(z)) \tilde{M}(z)$ must have a local maximum. But as $\hat{M}(z)$ is strictly increasing this leads to a contradiction.

Proof of $\partial R / \partial z>0$ for $M>\bar{M}_{N C}$ :

The agent's rent is given by

$$
\begin{aligned}
R= & (p+a(1-p)) b+a z D_{A}-c(a) \\
= & \left(p+A\left((1-p) b+z D_{A}\right)(1-p)\right) b \\
& +A\left((1-p) b+z D_{A}\right) z D_{A} \\
& -c\left(A\left((1-p) b+z D_{A}\right)\right) .
\end{aligned}
$$

Differentiation with respect to $z$ gives (for brevity the arguments of the functions are omitted)

$$
\begin{aligned}
\frac{\partial R}{\partial z}= & A^{\prime} \cdot(1-p) D_{A} b+A^{\prime} \cdot \frac{\partial b}{\partial z}(1-p)^{2} b+(p+A \cdot(1-p)) \frac{\partial b}{\partial z} \\
& +A^{\prime} \cdot z D_{A}^{2}+A^{\prime} \cdot(1-p) \frac{\partial b}{\partial z} z D_{A}+A \cdot D_{A} \\
& -c^{\prime} \cdot A^{\prime} \cdot\left((1-p) \frac{\partial b}{\partial z}+D_{A}\right) \\
= & \left(A^{\prime}(1-p) b+A+A^{\prime} z D_{A}-c^{\prime} A^{\prime}\right)\left((1-p) \frac{\partial b}{\partial z}+D_{A}\right)+p \frac{\partial b}{\partial z} \\
= & -\frac{p D_{A}}{1-p}
\end{aligned}
$$


because of (9).

Proof of Proposition 4:

The agent chooses $a=A((1-p) b+z \beta)$. The principal therefore solves

$$
\begin{array}{cl}
\max _{b, F} & (p+A((1-p) b+z \beta)(1-p))(M-b)-A((1-p) b+z \beta) z \beta \\
\text { s.t. } & b, \beta \geq 0 \\
& \beta \leq M-D_{P}
\end{array}
$$

The first derivatives of the principal's objective function are given by

$$
\begin{aligned}
& \frac{\partial \Pi}{\partial b}=(1-p)\left[A^{\prime}((1-p) b+z \beta)((1-p)(M-b)-z \beta)-A((1-p) b+z \beta)\right]-p \\
& \frac{\partial \Pi}{\partial \beta}=z\left[A^{\prime}((1-p) b+z \beta)((1-p)(M-b)-z \beta)-A((1-p) b+z \beta)\right] .
\end{aligned}
$$

Note that the terms in square brackets coincide in both expressions, and therefore $\frac{\partial \Pi}{\partial \beta}=\frac{z}{(1-p)}\left(\frac{\partial \Pi}{\partial b}+p\right)$. A strictly positive bonus $b>0$ implies that $\frac{\partial \Pi}{\partial b}=0$ and in turn $\frac{\partial \Pi}{\partial \beta}=\frac{p z}{(1-p)}>0$. Hence, $\beta=M-D_{P}$ whenever $b>0$. Furthermore, $\beta$ must be strictly positive, whenever $b=0$ as

$$
\left.\frac{\partial \Pi}{\partial \beta}\right|_{\beta=0, b=0}=z\left[A^{\prime}(0)(1-p) M\right]>0 .
$$

Three possible alternatives remain:

(i) $b=0, \beta<\Delta$ requires that $\left.\frac{\partial \Pi}{\partial \beta}\right|_{\beta=\Delta, b=0}<0^{12}$ which is equivalent to

$$
\begin{gathered}
z\left[A^{\prime}(z \Delta)((1-p) M-z \Delta)-A(z \Delta)\right]<0 \Leftrightarrow \\
M<\frac{1}{1-p}\left(\frac{A(z \Delta)}{A^{\prime}(z \Delta)}+z \Delta\right)=: M_{1}(z \Delta) .
\end{gathered}
$$

\footnotetext{
${ }^{12}$ The argument from footnotes 7 and 8 also applies here.
} 
The optimal strike price $\beta$ is then implicitly determined by

$$
\begin{gathered}
A^{\prime}(z \beta)((1-p) M-z \beta)-A(z \beta)=0 \Leftrightarrow \\
\beta=\frac{(1-p) M}{z}-\frac{A(z \beta)}{z A^{\prime}(z \beta)} .
\end{gathered}
$$

(ii) $b=0, \beta=\Delta$ requires that $\left.\frac{\partial \Pi}{\partial b}\right|_{\beta=\Delta, b=0} \leq 0$ and $\left.\frac{\partial \Pi}{\partial \beta}\right|_{\beta=\Delta, b=0} \geq 0$ which is equivalent to

$$
\begin{gathered}
(1-p)\left[A^{\prime}(z \Delta)((1-p) M-z \Delta)-A(z \Delta)\right]-p \leq 0 \text { and } \\
z\left[A^{\prime}(z \Delta)((1-p) M-z \Delta)-A(z \Delta)\right] \geq 0,
\end{gathered}
$$

which is equivalent to

$$
\begin{aligned}
& M \leq \frac{1}{1-p}\left(\frac{p+A(z \Delta)(1-p)}{A^{\prime}(z \Delta)(1-p)}+z \Delta\right)=: M_{2}(z \Delta) \text { and } \\
& M \geq \frac{1}{1-p}\left(\frac{A(z \Delta)}{A^{\prime}(z \Delta)}+z \Delta\right) .
\end{aligned}
$$

(iii) $b>0, \beta=\Delta$ requires that $\left.\frac{\partial \Pi}{\partial b}\right|_{\beta=\Delta, b=0}>0$ or

$$
\begin{gathered}
(1-p)\left[A^{\prime}(z \Delta)((1-p) M-z \Delta)-A(z \Delta)\right]-p>0 \Leftrightarrow \\
M>\frac{1}{1-p}\left(\frac{p+A(z \Delta)(1-p)}{A^{\prime}(z \Delta)(1-p)}+z \Delta\right)
\end{gathered}
$$

In that case the optimal bonus is determined by

$$
\begin{gathered}
A^{\prime}((1-p) b+z \Delta)((1-p)(M-b)-z \Delta)-A((1-p) b+z \Delta)=\frac{p}{1-p} \Leftrightarrow \\
b=M-\frac{1}{1-p}\left(\frac{p+A((1-p) b+z \Delta)(1-p)}{A^{\prime}((1-p) b+z \Delta)(1-p)}+z \Delta\right)
\end{gathered}
$$




\section{References}

Baker, G., Gibbons, R. and K.J. Murphy (1994): Subjective performance measures in optimal incentive contracts, Quarterly Journal of Economics 109, 1125-1156.

Baker, G., Gibbons, R. and K.J. Murphy (2002): Relational contracts and the theory of the firm, Quarterly Journal of Economics 117, 39-84.

Feess, E. and G. Muehlheusser (2005): Transfer fee regulations in European football, European Economic Review (forthcoming)

Fosfuri, A. and T. Ronde (2004): High-tech clusters, technology spillovers, and trade secret laws, International Journal of Industrial Organization $\mathbf{2 2}, 45-65$.

Gilson, R.J. (1999): The legal infrastructure of high technology industrial districts: Silicon Valley, Route 128, and covenants not to compete, New York University Law Review 74, 575-629.

Gibbons, R. and K.J. Murphy (1992): Optimal incentive contracts in the presence of career concerns: theory and evidence, Journal of Political Economy 100, 468-505.

Grossman, S.J. and O.D. Hart (1986): The costs and benefits of ownership: a theory of vertical and lateral integration, Journal of Political Economy 94, 691-719.

Hart, O.D. and J. Moore (1990): Property rights and the nature of the firm, Journal of Political Economy 98, 1119-1158.

Hellmann, T. and E. Perotti (2005): The circulation of ideas: firms versus markets. Discussion Paper.

Holmström, B. (1982): Managerial incentive problems - a dynamic perspective, in: Walross, B. (Ed.), Essays in Economics and Management in Honor of Lars Wahlbeck, Helsinki, 209-230. 
Kräkel, M. (2005): On the benefits of withholding knowledge in organizations, International Journal of the Economics of Business 12, 193-209.

Lembrich, G.T. (2002): Garden leave: a possible solution to the uncertain enforceability of restrictive employment covenants, Columbia Law Review 102, 2291-2323.

Nöldeke, G. and K.M. Schmidt (1995): Option contracts and renegotiation: A solution to the hold-up problem, Rand Journal of Economics 26, 163-179.

Nöldeke, G. and K.M. Schmidt (1998): Sequential investments and options to own, Rand Journal of Economics 29, 633-653.

Pakes, A. and S. Nitzan (1983): Optimum contracts for research personnel, research employment, and the establishment of "rival" enterprises, Journal of Labor Economics 1, 345-365.

Rajan, R.G. and L. Zingales (2001): The firm as a dedicated hierarchy: a theory of the origins and growth of firms, Quarterly Journal of Economics 116, 805-851.

Ronde, T. (2001): Trade secrets and information sharing, Journal of Economics and Management Strategy 10, 391-417.

Schmidt, K. and M. Schnitzer (1995): The interaction of explicit and implicit contracts, Economics Letters 48, 193-199.

Starr, M. and A.L. Strauss (2004): Non-competition by employee choice, National Law Journal. 